\title{
High dose intravenous vitamin c and metastatic pancreatic cancer: Two cases
}

\author{
Michael J. González ${ }^{1 *}$, Miguel J. Berdiel ${ }^{2}$, Jorge R Miranda-Massari ${ }^{3}$, Desireé López ${ }^{1}$, Jorge Duconge ${ }^{3}$, Joshua L. Rodriguez ${ }^{4}$ and Pedro \\ Adrover $^{4}$ \\ ${ }^{1}$ Medical Sciences Campus, Schools of Public Health, University of Puerto Rico, San Juan, Puerto Rico \\ ${ }^{2}$ Berdiel Clinic, Ponce, Puerto Rico \\ ${ }^{3}$ School of Pharmacy, University of Puerto Rico, San Juan, Puerto Rico \\ ${ }^{4}$ Ponce health Sciences University, Ponce, Puerto Rico
}

\begin{abstract}
Pancreatic cancer is considered an incurable disease. The survival rate of patients in all stages of the disease is poor. Overall, median survival is 3-5 months with a 12month survival rate of $10 \%$ and a 5 -year survival rate less than $5 \%$. Case report: We report a rare case of a long term survivor (2 years) of metastatic adenocarcinoma of the pancreas controlled with high dose intravenous Vitamin C with an acceptable performance status and quality of life.
\end{abstract}

\section{Introduction}

Pancreatic cancer is considered one of the most aggressive cancer types. According to the American Cancer Society pancreatic cancer is the fourth leading cause of cancer death in the United States in 2013 [1]. It is estimated that cancer in the pancreas has a 5 year survival rate of $6.7 \%[2,3]$. One of the reasons why pancreatic cancer has a poor survival rate is because, in many cases, it presents no symptoms until the cancer has reach metastasis [1]. Another reason why the pancreas is very difficult to evaluate in a physical examination is because of his troublesome location $[1,3]$. Indeed, in the past decades, the prognosis of pancreatic cancer mainly correlated with tumor stage has not been significantly improved by any procedure [4].

There are many studies where Vitamin $\mathrm{C}$ has been very effective in treating various types of cancer (5-7). Studies have shown that post intravenous vitamin C plasma at a levels of 350 to $400 \mathrm{mg} / \mathrm{dL}$ have been very toxic to human cancer cells [6]. Vitamin $\mathrm{C}$ also increases collagen production and enhances the immune system (6). It has been demonstrated that high dose intravenous vitamin $\mathrm{C}$ has given many cancer patients the opportunity to have a better quality of life [6-10].

\section{Case report \#1}

A case of a 59 year old Hispanic female patient suffering from pancreatic adenocarcinoma metastatic to the liver status post whipple procedure on November 2012. A computed tomography (CT) scan of the abdomen revealed an ill-defined, low attenuation mass at the head of the pancreas, measuring $3.0 \times 2.7 \mathrm{~cm}$. The patient was diagnosed in 2012 and completed chemotherapy in May 16, 2013. Her weight at this time was 130 pounds on a $5^{\prime} 7$ frame. On presentation, physical examination was notable for scleral icterus and jaundice. She presented cholelithiasis and a laparoscopic cholecystectomy was done. There were no palpable abdominal masses and no hepatosplenomegaly.

A blood analysis and a urinalysis were performed before the intravenous vitamin $\mathrm{C}$ treatment was started. Laboratory data showed elevated values of cholesterol $(311 \mathrm{mg} / \mathrm{dL})$, triglycerides $(430 \mathrm{mg} / \mathrm{dL})$, and carbohydrate AG 19-9 (288 U/mL).

The patient started the intravenous vitamin C treatment on May, 052013 and initially received three different doses of vitamin C the first week. The first dose was 25 gr of vitamin C (sodium ascorbate) in $250 \mathrm{cc}$ Ringer's lactated solution during 1 hour infusion. The second infusion was $50 \mathrm{gr}$ of vitamin C in $500 \mathrm{cc}$ of Ringer's lactated solution over a period of $1.5 \mathrm{hr}$. The third infusion was $75 \mathrm{gr}$ of vitamin $\mathrm{C}$ in $1,000 \mathrm{~mL}$ of Ringer's lactated solution over a period of $2 \mathrm{hrs}$. A maximum of 75 gr of vitamin C in 1,000 mL Ringer's lactated solution was given three times a week over a period of 2 months.

During high doses of intravenous vitamin C treatment, the laboratory data showed an important progress. Cholesterol and triglycerides values decreased to $266 \mathrm{mg} / \mathrm{dL}$ and $196 \mathrm{mg} / \mathrm{dL}$ respectively. Laboratory value of carbohydrate AG 19-9 lowered to $36 \mathrm{U} / \mathrm{mL}$ (normal range $0-35 \mathrm{U} / \mathrm{mL}$ ). No other treatment was given during IV Vitamin C therapy.

A whole body PET/CT study was performed on July 05, 2013. Her weight at this time was 140 pounds. The liver appeared enlarge with diffuse FDG activity. No focal areas of abnormal FDG uptake were noted within the hepatic parenchyma. The spleen, adrenal glands and visualized pancreatic portions demonstrate no area of abdominal FDG uptake. According to the PET/CT impression "no hypermetabolic foci to suggest F-18 FDG avid active neoplastic process or metastatic disease at present time." No adverse side effects were reported by the

Correspondence to: Michael J Gonzalez, Medical Sciences Campus, Schools of Public Health, University of Puerto Rico, San Juan, Puerto Rico, Tel: 787 6492737, E-mail: michael.gonzalez5@upr.edu

Key words: pancreatic adenocarcinoma, cancer of head of the pancreas, vitamin C

Received: December 06, 2016; Accepted: December 27, 2016; Published: December 29, 2016 
patient during and after the intravenous vitamin $\mathrm{C}$ treatment.

\section{Case report \#2}

A case of a 56 year old Hispanic male patient man with a medical history presenting hyperlipidemia, hypertension and diabetes, suffering from pancreatic adenocarcinoma metastatic to the liver status post whipple procedure on January 07, 2014. Metastatic process detected in two of five peripancreatic lymph nodes. A computed tomography (CT) scan of the abdomen revealed a moderately defined mass at the head of the pancreas, measuring $6.5 \times 4.5 \mathrm{~cm}$. He arrived to the clinic February 17, 2014 and was weighing 97 pounds in a 5'7 frame. On presentation, physical examination was notable for scleral icterus and jaundice. There were no palpable abdominal masses but hepatosplenomegaly was present. His peripheral laboratories revealed a total bilirubin of $10 \mathrm{mg} / \mathrm{dL}$ (normal range $0.3-1.9 \mathrm{mg} / \mathrm{dL}$ ), whereas the aspartate aminotransferase and alanine aminotransferase were 230 IU/L (normal range 8-48 IU/ L) and 615 IU/L (normal range 7-55 IU/L), respectively. Alkaline phosphatase was elevated at $245 \mathrm{IU} / \mathrm{L}$ (normal range 45-115 IU/L).

A blood analysis and a urinalysis were performed before the intravenous vitamin $\mathrm{C}$ treatment was started. Laboratory data showed elevated values of cholesterol $(250 \mathrm{mg} / \mathrm{dL})$, triglycerides $(320 \mathrm{mg} / \mathrm{dL})$, and carbohydrate AG 19-9 (59 U/mL). Carcino Embryonic Antigen (CEA) $6.5 \mathrm{Ng} / \mathrm{mL}$. Patient decided not to receive chemotherapy.

The patient started the intravenous vitamin $\mathrm{C}$ treatment on February 24, 2014 and initially received three different doses of vitamin $C$ the first week. The first dose was 25 gr of vitamin C (sodium ascorbate) in in 250cc Ringer's lactated solution during 1 hour infusion. The second infusion was $50 \mathrm{gr}$ of vitamin C in $500 \mathrm{cc}$ of Ringer's lactated solution over a period of $1.5 \mathrm{hr}$. The third infusion was $75 \mathrm{gr}$ of vitamin $\mathrm{C}$ in 1,000 mL of Ringer's lactated solution over a period of $2 \mathrm{hrs.} \mathrm{A}$ maximum of $75 \mathrm{gr}$ of vitamin $\mathrm{C}$ in 1,000 mL Ringer's lactated solution was given three times a week over a period of 6 months.

During high doses of intravenous vitamin $\mathrm{C}$ treatment, the laboratory data showed important progress. Cholesterol and triglycerides values decreased to $170 \mathrm{mg} / \mathrm{dL}$ and $180 \mathrm{mg} / \mathrm{dL}$ respectively. Laboratory value of carbohydrate AG $19-9$ lowered to $20 \mathrm{U} / \mathrm{mL}$ (normal range 0-35 U/mL). Carcino Embryonic Antigen lowered to $1.45 \mathrm{Ng} / \mathrm{mL}$ (normal range $<2.5 \mathrm{Ng} / \mathrm{mL}$ ). No other treatment was given during IV Vitamin C therapy.

A whole body PET/CT study was performed on August 27, 2014. The liver appeared slightly enlarge with no FDG activity. No focal areas of abnormal FDG uptake were noted within the hepatic parenchyma. The spleen, adrenal glands and pancreatic portions showed no area of abdominal FDG uptake. According to the PET/CT impression "no hypermetabolic foci to suggest F-18 FDG avid active neoplastic process or metastatic disease at present time." The patient's weight went up to 145 pounds. No adverse side effects were reported by the patient during and after the intravenous vitamin $\mathrm{C}$ treatment.

\section{Discussion}

During high doses intravenous vitamin $\mathrm{C}$ treatment the patients showed improvement not only in laboratory values of cholesterol, triglycerides, carbohydrate AG-19 and CEA but in the way they were capable of renewing activities of daily living. High doses of intravenous vitamin $\mathrm{C}$ have demonstrated promising results in the treatment of cancer in every stage. Some studies in vitro show that high doses of vitamin $\mathrm{C}$ produce hydrogen peroxide which is very toxic to tumor cells which lack the necessary enzymes (catalase and glutathione peroxidase) to get rid of it [7]. Also Padayatty et al., 2006 suggested that high plasma concentration of vitamin $\mathrm{C}(14,000 \mu \mathrm{mol} / \mathrm{L})$ acts as a pro-drug for the formation of hydrogen peroxide in extracellular fluid which causes a toxic reaction in cancer cells [7].

Our data supports that the treatment of high dose intravenous vitamin $\mathrm{C}$ can be used in the management of patients with pancreatic cancer with improvement the quality of life.

\section{References}

1. Cancer Facts \& figures 2013. (n.d.).American Cancer society. Retrieved September 20,2014. [http://www.cancer.org/acs/groups/content/@epidemiologysurveilance/ documents/document/acspc-036845.pdf]

2. Surveillance, Epidemiology, and End Results ProgramTurning Cancer Data Into Discovery. (n.d.). Cancer of the Pancreas. Retrieved September 20, 2014. [http://seer. cancer.gov/statfacts/html/pancreas.html]

3. Pancreatic Cancer Facts 2014. (n.d.).Pancreatic Cancer Action Network. Retrieved September 20, 2014. [http://www.pancan.org/wp-content/uploads/2014/04/pancreatic cancer_media_facts.pdf]

4. Matsuno S, Egawa S, Arai K (2001) Trends in treatment for pancreatic cancer. $J$ Hepatobiliary Pancreat Surg 8: 544-548. [Crossref]

5. Jackson J, Hunninghake R., Kirby R, Krier C, Lewis R (2008). A child with metastatic sarcoma and a patient with cancer of the head of the pancreas. J Orthomolec Med 23 41-42.

6. Riordan ND, Riordan HD, Casciari JJ (2000) Clinical and experimental experiences with intravenous Vitamin C. J Orthomolec Med 15: 201-213.

7. Jackson J, Riordan HD, Hunninghake R, Riordan ND (1995) High dose intravenous vitamin $\mathrm{c}$ and long time survival of a patient with cancer of the head of the pancreas. $J$ Orthomolec Med 10: 87-88

8. Padayatty SJ, Riordan HD, Hewitt SM, Katz A, Hoffer LJ, et al. (2006) Intravenously administered vitamin $\mathrm{C}$ as cancer therapy: three cases. CMAJ 174: 937-942. [Crossref]

9. Riordan HD, Riordan NH, Jackson JA, Casciari JJ, Hunninghake R, et al. (2004) Intravenous vitamin $\mathrm{C}$ as a chemotherapy agent: a report on clinical cases. $P R$ Health Sci J 23: 115-118. [Crossref]

10. Duconge J, Miranda-Massari JR, Gonzalez MJ, Riordan ND, Riordan HD, et al. (2007) Vitamin C Pharmacokinetics after Continuous IV Infusion in a Patient with Prostate Cancer. The Ann Pharmacother 41: 1082-1083.

Copyright: (C)2016 González MJ. This is an open-access article distributed under the terms of the Creative Commons Attribution License, which permits unrestricted use, distribution, and reproduction in any medium, provided the original author and source are credited. 